\title{
II. ESTUDIOS
}

\section{REPRESENTACIÓN BURLESCA DE LOS BLASONES EN GRAN SEÑOR Y RAJADIABLOS}

\author{
Luis Hermosilla \\ Kent State University \\ lhermosi@kent.edu
}

\section{RESUMEN / ABSTRACT}

En este ensayo se analiza el repertorio de recursos satíricos empleados por Eduardo Barrios en Gran Señor y rajadiablos en la confección de un relato humorístico que socava la percepción ideológica que privilegiaba la fama del apellido y del linaje peninsular como signos hegemónicos del estatus aristocrático. Mediante la caricaturización literaria de las cadenas emblemáticas asociadas al fuero de los Casaquemada y el escudo de armas de los antepasados de los Valverde, Eduardo Barrios pone de relieve la persistencia ideológica, en algunos sectores de la sociedad chilena representada en la novela, de un sistema anacrónico de diferenciación social incompatible con el nuevo ideario democrático impulsado con el advenimiento de la república.

PALABRAS ClaVE: rajadiablos, sátira, blasones, linaje, Eduardo Barrios.

This essay analyses the array of satirical resources employed by Eduardo Barrios in his Gran Señor y rajadiablos (Great Lord and Hell Raiser) to create a humoristic narration undermining the ideological perception that favored the Peninsular last name and lineage as hegemonic signs of aristocratic status. Through a literary caricature-like representation of the emblematic chains related to the Casaquemada court of justice and the Valverde predecessors' coat of arms, Barrios satirizes the persistence of an anachronic ideology of social differentiation held by some sectors of the Chilean society represented in this novel. Such ideology becomes incompatible with the new democratic ideals brought along by the emerging Republic.

KEY WORDS: Hell Raiser, satire, coat of arms, lineage, Eduardo Barrios. 
En el ámbito de la literatura chilena, Eduardo Barrios es ponderado como uno de los escritores 'de registro creador más completo' (Fernández Fraile 359). En su obra se registra un variado repertorio de tendencias literarias, en cuya nómina cabe mencionar el costumbrismo, el naturalismo, el análisis de carácter sicológico, el relato de trasfondo histórico y la pintura de tipos de la clase media chilena. A la lista anterior puede agregarse la vertiente humorística, faceta en la escritura de Eduardo Barrios que, además de estar patente en sus sainetes y en algunos de sus cuentos, se verifica también en el diseño satírico conferido a un número significativo de pasajes de su reconocida novela Gran Señor y rajadiablos (1948).

Gilbert Highet, en The Anatomy of Satire, considera que en lo que respecta a los géneros de ficción dramática o narrativa la calificación de sátira aplica solamente a las obras predomintemente satíricas: "When we speak of satires in fiction (whether narrative or dramatic) we shall mean only those books which are predominantly satirical, not those which now and then drop into satire but mainly designed to present a richer and more balanced picture of life" (158). Aunque Gran Señor y rajadiablos no pertenece al género de la sátira narrativa, su componente satírico parcial no manifiesta una gestación aislada o aleatoria, ni está marginada de la envergadura concedida al contexto histórico-social en esa novela ${ }^{1}$.

En este ensayo se analiza el repertorio de recursos empleados por Eduardo Barrios en la confección de un relato satírico que impugna la percepción ideológica que privilegiaba la fama del apellido y el linaje peninsular como signos hegemónicos del estatus aristocrático. Mediante la caricaturización literaria de las cadenas emblemáticas asociadas al fuero de los Casaquemada y el escudo de armas de los antepasados de los Valverde, Eduardo Barrios pone de relieve la persistencia ideológica, en algunos sectores de la sociedad chilena representada en la novela, de un sistema anacrónico de diferenciación social incompatible con el nuevo ideario democrático impulsado con el advenimiento de la república.

1 Siguiendo los juicios emitidos por José Zamudio, el investigador Máximo Fernández Fraile contextualiza la posición que ocupa Gran Señor y rajadiablos en el corpus de novela histórica nacional chilena como una obra que se caracteriza por ser 'una interpretación de las realidades social, histórica, geográfica y humana, con menos 'historicismo' -el de la historia consagrada y oficial- pero con más dimensión vital, en que se captan inquietudes, ambientes, colectividades humanas'(362). 
Luis Barros y Ximena Vergara, en el libro El modo de ser aristocrático: el caso de la oligarquía chilena hacia 1900, consignan la coexistencia de dos ópticas excluyentes en la percepción del estatus aristocrático en los sectores oligárquicos de la sociedad chilena en los albores del siglo XX. A partir del examen de las novelas de corte realista escritas en Chile durante las dos primeras décadas del siglo $\mathrm{XX}^{2} \mathrm{y}$ de diversos textos históricos y culturales, concluyen que en esa época: "de un lado, se percibe lo aristocrático fundamentalmente a partir del dinero, afirmando su necesariedad y suficiencia. De otro, se enfatiza el linaje como condición obligada de lo aristocrático. Vemos entonces que el dinero y el apellido no están necesariamente integrados en la conciencia oligárquica de la época y que ésta, por el contrario, acusa dos puntos de vista que tienden a negarse recíprocamente" (133). Aunque por su fecha de publicación, 1948, Gran Señor y rajadiablos no corresponde al corpus literario analizado por Luis Barros y Ximena Vergara, el tiempo histórico en que se desarrolla la acción de esta novela comprende el periodo de mediados del siglo XIX y abarca varias décadas del siglo XX. Semejante a los hallazgos producidos por el estudio realizado por Luis Barros y Ximena Vergara, en el universo novelesco de Gran Señor y rajadiablos el cura José María Valverde articula una defensa del apellido y el linaje ${ }^{3}$ peninsular como condición obligada del prestigio aristocrático. En una posición antinómica,

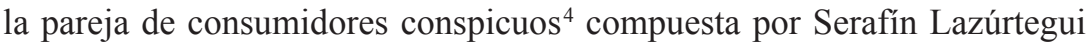

2 De la muestra novelística analizada por esos investigadores caben señalarse los siguientes títulos: Un mundo que se fue, de Eduardo Balmaceda Valdés; Un idilio nuevo, Casa grande y En familia, de Luis Orrego Luco; Días de campo, de Federico Gana y Cuando mi tierra fue moza, de Inés Larraín.

${ }^{3}$ Luis Barros y Ximena Vergara consideran que: "La tradición a que liga el linaje no es otra que los valores y las costumbres que han ido cristalizando junto con la vieja estructura de la hacienda" (132). Se preguntan que "¿si no es en el dinero y el buen tono donde las oligarquías de provincia fincan su identidad aristocrática, dónde pueden fincarla que no sea el linaje?" (132).

${ }^{4}$ Manuel Vicuña Urrutia destaca el incremento de la capacidad adquisitiva del sector adinerado de la oligarquía chilena de mediados del siglo XIX y su papel como consumidores de productos extranjeros. Aclara que si bien es cierto que el fenómeno del consumo conspicuo y la adopción de la moda como signos de distinción social por parte de la élite adinerada alcanzan una mayor visibilidad en 1900, como lo señalan Luis Barros y Ximena Vergara, el debut de esos rituales retrotrae a mediados del siglo XIX (39). 
y misia Jesús Aldana, se acoge a los rituales del buen tono ${ }^{5}$, en el medio santiaguino, como forma de ostentar prestigio aristocrático.

Northrop Frye señala que en el género de la sátira, el conflicto cómico se estructura mediante el enfrentamiento de dos sociedades, una concebida como normal y la otra como absurda (29). Gilbert Highet, por su parte, especifica el tipo de oposición binaria presente en las sociedades conceptualizadas como contrapuestas en la sátira: "But satire does not usually compare two real societies: it compares a real and an ideal, or a noble dream with a debased reality" $(159)^{6}$. En contraposición con la aristocracia criolla ostentada por los sectores oligárquicos adinerados, Eduardo Barrios impregna el lente ideológico del cura Valverde con una máscara obsoleta que vocaliza la sumisión a los conceptos del linaje y el apellido como signos hegemónicos del prestigio aristocrático. Aunque José María Valverde impugna los mecanismos de ascenso empleados por diversos miembros del sector oligárquico adinerado para alcanzar "prosapia criolla", esos medios constituían, en efecto, los dispositivos oficiales de movilidad social en el territorio chileno durante la época colonial. El historiador Alfredo Jocelyn-Holt señala que en los siglos XVII y XVIII "el acceso al estrato alto fue siempre relativamente fluido y dependió de multiplicidad de fuentes de poder" (89). Afirma que "es posible constatar una progresión social arquetípica que comienza con la acumulación de riqueza en el ámbito mercantil, es seguida por la compra de propiedades agrícolas y culmina invariablemente con la obtención de cargos públicos y honores" (88). Consigna que "la riqueza constituyó un mecanismo de ascenso

5 Por buen tono se entendía en la época el despliegue de un conjunto de actividades, tertulias, cenas, bailes, kermesses, teatro, temporadas veraniegas y viajes a Europa, entre otras, realizadas por el sector adinerado de la oligarquía como signos de distinción social. Luis Barros y Ximena Vergara destacan la sumisión a los avatares de la moda europea elegante y refinada como el común denominador del buen tono nacional chileno: "El buen tono apunta a una vasta gama de patrones de conducta cuyo denominador común es el de estar regidos por la moda, vale decir, por esa convención que define todo aquello que es tenido por elegante y refinado. De manera asaz, caprichosa y voluble, la moda erige usos y ademanes, lugares y cosas, formas de reunión y aficiones, en símbolos de suprema distinción. Vasta es la imaginaria de la moda, ella puede, sin embargo, resumirse en una actividad: el consumo conspicuo realizado bajo la forma de un rito colectivo" (59.

${ }^{6}$ A diferencia de los lazos creados por el humor, Alfred Stern subraya el elemento de la separación como un subproducto de la sátira: "al provocar una risa casi universal, el humor crea un lazo entre los hombres, mientras que la sátira separa a uno de los otros" (107). Ana María Zubieta, por su parte, considera que la sátira "busca más bien degradar los valores colectivos de grupos o personajes" (66). 
social" (88) y que "la participación en actividades comerciales no constituyó una causa de estigma social" (89). Subraya los vínculos del llamado 'vecindario noble' del siglo XVIII con las actividades comerciales:

Efectivamente, todas las familias del siglo XVIII pertenecientes al llamado 'vecindario noble' tenían vínculos comerciales actuales o previos. Cabe señalar además que esta progresión arquetípica de ascenso social fue relativamente rápida durante el siglo XVIII. Permitió la promoción social de nuevos grupos inmigrantes -entre los cuales se destaca un número significativo de comerciantes y funcionarios reales de origen vasco- a los niveles más altos en solo una o dos generaciones. En suma, la supuesta 'aristocracia' de fines del siglo XVIII es relativamente nueva; no se remonta necesariamente a un pasado encomendero o a un linaje peninsular (89).

En contraste con los vínculos comerciales que tenían las familias de la llamada 'aristocracia' criolla de fines del siglo XVIII, el cura José María destaca la filiación genealógica de los Valverde con el sector terrateniente de origen colonial y encomendero. Al referirse a los terrenos del fundo La Huerta, hace referencia a una sucesión de propietarios cuyas tierras fueron otorgadas inicialmente al capitán Valverde por el Gobernador General, mediante el sistema de encomiendas: "Pertenecieron estos terrenos, ab initio, a los abuelos, entre varias encomiendas que los Valverde hubieron del Gobernador General, y como herencia los recibió solo José Vicente" (17). Funda parte de la fama de su apellido paterno en la actuación de fray Vicente Valverde en la conquista española del imperio incaico. Argumenta que como personero de Carlos V y acompañante de Francisco Pizarro, al dominico fray Vicente Valverde le cupo el "honor" de atestiguar la implantación de la soberanía política de la monarquía española en el Cuzco y de proclamar el reemplazo del dios sol por la figura de Jesucristo.

José María Valverde principia la narración oral de la crónica sobre los Valverde con una pregunta retórica que objeta la ignorancia de su sobrino sobre su identidad y el abolengo de sus ancestros:

¿Sabes tú quién eres? ¿Sabes quiénes somos los Valverde? Descendemos de aquel fray Vicente Valverde que acompañó a Francisco Pizarro en la conquista del Cuzco. Este dominico fue quien, tras de presenciar y atestiguar ante escribano el descenso del inca Atahualpa, proclamó ante los trescientos mil indios de la capital incásica que si la soberanía de Carlos V reemplazaba desde entonces a la del inca, se ponía también 
el dios sol en el imperio indígena, para que solo resplandeciera en él Jesucristo Nuestro Señor. Hermano de fray Vicente fue tu tatarabuelo, don Joseph. Tu padre llevó ambos (76).

En su función como glosador irónico de la crónica familiar articulada por José María Valverde, el narrador omnisciente de la novela pone énfasis en destacar la efervescente altisonancia elocutiva empleada por el cura para autorizar la importancia de los hechos narrados: "fueron encendiendo al cura los ecos de sus palabras, a las que voluntariamente imprimía cadencias y estilo de infolio" (76). La glosa burlesca realizada por el narrador transforma el arcaísmo del estilo de infolio remedado por el cura Valverde en un recurso paródico que ridiculiza el anacronismo de las ínfulas elitarias fundamentadas en la fama alcanzada por los ancestros en la empresa de la conquista.

En contraste con la práctica de obtener títulos nobiliarios mediante el sistema de compra y venta disponible durante la época colonial, el cura Valverde resalta la raigambre peninsular del estatus aristocrático de sus ancestros y la actuación de esa rama familiar en el escenario de la corte. Como monteros de Carlos V, los Valverde participaban con el monarca en el deporte de la caza, actividad prototípica de la aristocracia. El cura refiere que esa rama cortesana de los Valverde legó escudo de armas a los sucesivos descendientes de ese apellido: "No podría yo entrar en muchos pormenores de la heráldica, ciencia tan historiada, pero sí agregar que los Valverde, en España monteros del rey, nos legaron escudo: seis galgos atigrados se tienden a carrera sobre campo de sinople" (76). Concluye la descripción del escudo familiar con una frase admirativa que revela el orgullo que le produce la rememoración de ese emblema: “¡Espléndido blasón!” (76). Es importante resaltar el carácter retrógrado que reviste la añoranza de ese signo heráldico, en un momento histórico en que ya se había producido la remoción de los escudos de armas en la república chilena.

Tras consignar el sello aristocrático del apellido Valverde, el cura testifica sobre la ascendencia hidalga de sus ancestros por la línea materna. Los Casaquemada eran: "vástagos de cierto hidalgo castellano que con sus seis hijos varones y un puñado de siervos batió a los moros después de incendiar la propia mansión, en lúcida estratagema" (77). La heroicidad atribuida al hidalgo Casaquemada se fundamenta en su participación, junto a sus hijos y "un puñado de siervos," en una cruzada victoriosa que contribuyó a expulsar a los musulmanes de la Península Ibérica. 
Henri Bergson identifica la rigidez u obstinación mental que demuestran los personajes que insisten en conformar su conducta como una adaptación al pasado en lugar de hacerlo en consonancia con las demandas del presente, como uno de los elementos generadores de un efecto cómico que convoca la risa:

Let us try to picture to ourselves a certain inborn lack of elasticity of both senses and intelligence, which brings it to pass that we continue to see what is no longer visible, to hear what is no longer audible, to say what is no longer the point: in short, to adapt ourselves to a past and therefore imaginary situation, when we ought to be shaping our conduct in accordance with reality which is present (11).

La obstinación mental del cura Valverde con el abolengo y los antiguos símbolos emblemáticos de la estirpe lo impulsa a añorar un signo de distinción social carente de visibilidad en el nuevo contexto social republicano. Su anquilosado orgullo clasista continúa atribuyéndole a los escudos de armas la importancia que tenían en el imaginario de la sociedad estamental peninsular. Eduardo Barrios exacerba el perfil que exhibe la osificación mental de José María Valverde con las señas emblemáticas de la estirpe mediante la desfiguración burlesca de los símbolos heráldicos del escudo de armas del hidalgo Casaquemada, "la casa en llamas bajo arco de siete estrellas -los siete varones cristianos- en lo alto del cielo, y entre la mansión y el arco, la media luna mora despeñándose a la hoguera" (77). La caricaturización del triunfo apoteósico de los cristianos en la Reconquista, codificado en los símbolos emblemáticos del escudo de los Casaquemada, carnavaliza la envergadura heroica de la participación del hidalgo Casaquemada en esa hazaña histórica y ridiculiza los fundamentos discursivos de la retórica de la fama de la estirpe articulada por el cura Valverde.

Como narratario o receptor interno de la crónica oral que celebra las hazañas heroicas del hidalgo Casaquemada, el joven Valverde reacciona con una sonrisa enigmática que introduce el elemento de la ambigüedad y genera la formulación de interpretaciones discrepantes. José María Valverde interpreta la sonrisa de su sobrino como un gesto de burla irreverente a los antepasados y lo amonesta asignándole un destino señorial: "Deja la interjecciones risueñas. Estás llamado a ser siempre gran señor” (77). No obstante, en su función como glosador irónico, el narrador omnisciente aclara el significado ulterior de la sonrisa de José Pedro como una manifestación de complacencia: "en verdad, no escondía el muchacho ánimo de burla, antes bien, los gentiles 
de su ayer parecían acudir a inflarle de orgullo el pecho. Sí; él sentíase gran señor y amaba ese sentimiento" (77). Edgar Johnson, en A Treasury of Satire, destaca la función de la ironía como una de las estratagemas más poderosas de la sátira indirecta, y la labor del ironista como un fingidor consumado en el arte de decir lo contrario de lo que dice:

Irony overstates what we don't mean and carefully understates what we do mean. From this derived the popular conception of irony as confined to saying the opposite of what we mean. For if we keep on saying less and less of what we really mean, it follows that we are also saying more and more of what we don't mean, until at last the intensification of understatement results in inversion (25).

La entonación irónica empleada por el narrador omnisciente para aclarar el enigma de la sonrisa de José Pedro subvierte el significado literal de la proposición enunciada y se burla, en el fondo, del sentimiento señorial que invade al "llamado a ser siempre gran señor (77). El empleo de ese recurso revela una notable semejanza con la pretensión de inocencia fingida por el ironista:

By such an appearance of innocence the ironist gives the impression that satire was far from his intention. Any unveiling he has achieved seems less of his engineering than inhererent in circumstances themselves. The fact seems their own satire. This is much more persuasive than if the satirist appears to be calling our responses for us (Johnson 26).

El elemento de la ambigüedad atribuida a la sonrisa de José Pedro Valverde permite formular una sátira bidimensional que socava las ínfulas señoriales de José María Valverde y el orgullo de la estirpe recién acunado en el joven Valverde.

La identificación de José Pedro como futuro "gran señor" deja claro que el cura Valverde no solo visualiza a su sobrino como miembro de una élite cuyos méritos heredados a través del linaje legitima la superioridad de su posición social, sino también como un ente destinado a conservar mediante sus acciones el buen nombre de la familia. A tono con esas expectativas, el cura instruye a José Pedro sobre el derecho de asilo de que gozaban los descendientes del hidalgo Casaquemada, tanto en España como en el territorio colonial: 
- Por el fuero de Casaquemada - continuó el clérigo- disfrutamos siempre, en España y aquí, derecho de asilo.

-¿De modo que si nosotros pusiéramos cadenas a esta casa. . .?

- Nadie tendría derecho a violarla. Pero ... son otros los tiempos.

- No. Yo creo que no han variado como para renunciar a este privilegio ... Yo voy a poner esas cadenas. Y juro que las respetarán.

- Quijotería. Sin embargo ... quién sabe si te sobre razón (77).

Ante la determinación de José Pedro de reivindicar el derecho de asilo e instalar las cadenas emblemáticas de la mansión inviolable en el fundo La Huerta, José María Valverde se sitúa en un terreno fronterizo, a medio camino entre su obstinación mental con el abolengo de la estirpe y la aceptación de la realidad histórica del presente. Admite la falta de vigencia de los fueros estamentales en los estatutos jurídicos de la nación chilena cuando reconoce que "son otros los tiempos" (77). Aunque califica el proyecto de su sobrino como "quijoterías", mantiene una reticencia solapada a renunciar a los privilegios adscritos, aspecto que se torna evidente cuando concede "quién sabe si te sobre razón" (77). La recepción ideológica de la crónica oral que encumbra la fama del apellido de los Valverde y el abolengo de la estirpe de los Casaquemada produce un efecto determinante en la construcción de la identidad y las actitudes señoriales de José Pedro Valverde.

En El París americano, la oligarquía chilena como actor urbano en el siglo XIX, Manuel Vicuña Urrutia señala la crisis identitaria y el sentimiento de inseguridad comunitaria que debió haber generado en la élite chilena la abolición del antiguo sistema de títulos y signos emblemáticos: "Quizás este sentimiento explique que los miembros de la élite, a comienzos de los años 1850 's y pese a decirse republicanos, todavía no hubieran renunciado ni al orgullo de su 'sangre azul', ni al gusto que les producía el escuchar que se refirieran a ellos haciendo uso de sus ya caducos títulos nobiliarios" (29). Considera que "cuando las formas de diferenciación social tienden a diluirse en una esfera, comúnmente se ponen en práctica otras instancias capaces de cumplir similar acometido" (29). Años más tarde, en su función social como patrón señorial de La Huerta, José Pedro Valverde reactiva las antiguas instancias de diferenciación social asociadas a su estirpe para demandar respeto y soberanía en el territorio de su fundo. Instala, en el presente del Chile republicano, las cadenas emblemáticas de la mansión inviolable, invocando el derecho de asilo otorgado a sus ancestros en la sociedad estamental española. Aunque el símbolo de las cadenas está vinculado históricamente 
con las hazañas heroicas del hidalgo Casaquemada, aviva en José Pedro el orgullo de pertenecer a la estirpe de fray Vicente Valverde. La obstinación mental de José Pedro ${ }^{7}$ con los signos emblemáticos de la estirpe aparece explícitamente mediatizado por su posición como consumidor ideológico de la crónica oral narrada por su tío:

Y se dirige a visitar las cadenas, sus cadenas, el símbolo de mansión inviolable que ha puesto ya en el frente de la casa, cerrando el jardín. Sopesar, contar los cuatrocientos eslabones de hierro negro, cerco de veinte combas entre las estacas de luma, le inflaman de orgullo el pecho, cual si en su interior se levantase a través de los siglos aquel fray Vicente Valverde, personero de Cristo y de Carlos V en el Perú de Atahualpa. [...]. Desde que tendió esas cadenas ha cobrado vigor extraordinario para el Valverde la razón de estirpe. 'Casa con cadenas, casa de mucho respeto' (146).

Henri Bergson destaca el elemento de la inconsciencia como un atributo que caracteriza la actitud del sujeto cómico ante los componentes risibles de su conducta, ya que se tornan invisibles para el mismo y visibles para el resto de los espectadores: "The comic person is unconscious[ . . .] he becomes invisible to himself while remaining visible to all the world" (16). En el pasaje siguiente, José Pedro Valverde aparece posicionado como un sujeto inconsciente del efecto cómico que generan los actos mediante los cuales expresa su vanidad linajuda. En su función como espectador de esos actos, el narrador omnisciente los convierte en objeto de escarnio en su reprimenda explícita:

Sí. Obraron desde un principio las cadenotas con el poder que símbolos y emblemas tienen siempre sobre las vanidades del hombre. Y obran ahora, reanimándole dentro de la conciencia cuando el sacerdote le contara sobre sus abolengos. Aún más, no le satisface ya el solo

7 En Gran Señor y rajadiablos, Eduardo Barrios elabora una caracterización compleja del personaje José Pedro Valverde que no se limita a presentar sus actitudes señoriales y su comportamiento semifeudal en el fundo La Huerta. Para un análisis que toma en cuenta la introspección meditativa y el perfil sicológico del protagonista de esa novela, véase, por ejemplo, Los personajes en la obra de Barrios, de Silvia Martínez Dacosta. La ambivalencia de José Pedro, como personaje que integra las facetas del espíritu nacional de la época, representado por la civilización y la barbarie, ha sido estudiada por John Walker en el artículo "The theme of 'Civilization y Barbarie' in Gran Señor y rajadiablos". 
mirarlas, pósale por un instante la mano encima, en actitud de dominio, y luego penetra en su solar con soberbio paso (146).

Aferrado a los conceptos señoriales de la estirpe y amparándose en los privilegios otorgados a sus antepasados en un fuero caduco, el voluntarismo de José Pedro Valverde choca finalmente con el ideario jurídico del gobierno republicano. Se enfrenta con los agentes de la autoridad estatal que, en nombre de los funcionarios fiscales, le exigen sellar el alambique. Sin restarle importancia al substrato socio-jurídico, es pertinente observar cómo en algunos pasajes de la novela, Eduardo Barrios carnavaliza la escenificación de ese conflicto rebajándolo al terreno cómico-satírico. Sirva como ejemplo la comicidad producida por el registro lingüístico empleado por Bruno para reportar el enfrentamiento protagonizado por los polizontes del Estado, degradados a la categoría de pacos, y el batallón bravo de La Huerta, protectores leales del derecho de asilo y la inviolabilidad territorial del fundo La Huerta:

La indiaá, patrón que se les desató a los pacos éstos. De balde les dije que si no veidan las cadenas, que si no sabían que la casa suya no la puede atropellar ni la misma autoridá. Inútil. A bulla de golpes que salía de la bodega, figurándose sabe Dios qué, quisieron meterse pa adentro. Ya se habían enrabiado cuando su mercé los trató de pacos. Y contimás, que aquí los niños los paquearon también su poco ... Total, patrón, que uno largó un tiro al aire y se armó la de paire y señor mío (298).

Mediante la transgresión de las barreras que delimitan lo serio de la burla, Eduardo Barrios carnavaliza la yuxtaposición de dos sistemas de jurisprudencia, uno representativo del viejo orden estamental y el otro asociado con el nuevo orden jurídico instalado en la república ${ }^{8}$.

${ }^{8}$ La representación carnavalesca de los emblemas y de los individuos que protagonizan el conflicto entre el viejo y el nuevo orden jurídico en la novela Gran Señor y rajadiablos puede ser conectada con los conceptos bakhtinianos que destacan la naturaleza dual y ambivalente de las imágenes del carnaval y su conexión con los cambios y las crisis que producen la destrucción y la renovación: "We most consider again in more detail the ambivalent nature of carnival images. All images of carnival are dualistic; they unite within themselves both poles of change and crisis: birth and death (the image of pregnant death), blessing and curse (benedictory carnival curses which call simultaneously for death and rebirth), praise and abuse, youth and old age, top and bottom, face and backside, stupidity and wisdom" (Problems of Dostoevsky's Poetics, 126). 
En resumen, amparándose en el uso de recursos como la ironía, la caricaturización literaria, la desacralización de emblemas revestidos de valor simbólico y la pretensión de inocencia, el narrador omnisciente de la novela Gran Señor y rajadiablos ridiculiza el apego retrógrado de José María Valverde a los conceptos de la fama del apellido y el linaje peninsular de la estirpe, conceptos enraizados en la escala de valores de la jerarquía estamental de la antigua metrópoli. Satiriza, además, la tentativa anacrónica de José Pedro Valverde, protagonista de Gran Señor y rajadiablos, de restituir, en el nuevo contexto socio-jurídico del Chile republicano, los privilegios adscritos a sus ancestros españoles durante la época de la Reconquista. Mediante un diseño satírico que carnavaliza la obstinación ideológica de los Valverde con los emblemas heráldicos y los fueros anacrónicos, Eduardo Barrios pone de relieve la persistencia ideológica, en la sociedad chilena representada en la novela, de un sistema de diferenciación social incompatible con el nuevo ideario democrático impulsado con el advenimiento de la república. Los pasajes de Gran Señor y rajadiablos analizados en este ensayo permiten a su vez desvelar la faceta de Eduardo Barrios como artífice consumado de la ironía, recurso fundamental de la sátira.

\section{BIBLIOGRAFÍA}

Balmaceda Valdés, Eduardo. Un mundo que se fue. Santiago de Chile: Andrés Bello, 1969.

Bakhtin, Mikhail. Problems of Dostoevsky's Poetics. Ed. Trad. Caryl Emerson. Minneapolis: U of Minnesota P, 1984.

Barrios, Eduardo. Gran Señor y rajadiablos. Santiago de Chile: Andrés Bello, 1981.

Barros Lezaeta, Luis y Ximena Vergara Johnson. El modo de ser aristocrático: el caso de la oligarquía chilena hacia 1900. Santiago de Chile: Ediciones Aconcagua, 1978.

Bergson, Henri. Laughter: An Essay on the Meaning of the Comic. Trans. Clauderesly Brereton y Fred Rothwell. Los Angeles, CA: McMillan\& Co, 1911.

Fernández Fraile, Máximo. La crítica literaria en Chile. Santiago, Chile: Edebé, 2003.

Frye, Northrop. Anatomy of Criticism. Princeton, NJ: Princeton UP, 2000.

Gana, Federico. Obras completas: Días de campo. Otros cuentos. Santiago, Chile: Nascimento, 1965.

Highet, Gilbert. The Anatomy of Satire. Pinceton, NJ.: Princeton UP, 1972.

Jocelyn-Holt, Alfredo. La independencia de Chile: tradición y mito. Madrid: MAPFRE, 1992.

Johnson, Edgar. A Treasury of Satire. New York: Simon and Schuster, 1945.

Larraín, Inés. Cuando mi tierra fué moza. Santiago, Chile: Nascimento, 1943. 
Martínez Dacosta, Silvia. Los personajes en la obra de Barrios. New York: Senda Nueva de Ediciones, 1990.

Orrego Luco, Luis. Un idilio nuevo. Santiago de Chile: Zig-Zag, 1913. Casa grande. Santiago de Chile: Zig-Zag, 1961. En familia. Santiago de Chile: Zig-Zag, 1912.

Stern, Alfred. Filosofia de la risa y del llanto. Barcelona: Editorial Universitaria, 1975.

Vicuña Urrutia, Manuel. El París americano, la oligarquía chilena como actor urbano en el siglo XIX. Santiago, Chile: Universidad Finis Terrae, Museo Histórico Nacional, 1996.

Walker, John. "The theme of 'Civilization y Barbarie' in Gran Señor y rajadiablos". Hispanófila 42 (1971): 57-67.

Zubieta, Ana María. "El humor y el problema de narrar las diferencias". Escritura 33-34 (1976): 61-82. 